\title{
Changing trends in the indication of caesarean delivery in multigravida- experience from a referral center in Eastern India: a prospective study
}

\author{
Nikhil Sebastian*, Anup Pradhan, Pesona Grace Lucksom
}

Department of Obstetrics and Gynecology, Sikkim Manipal Institute of Medical Sciences, Gangtok, Sikkim, India

Received: 17 May 2020

Accepted: 29 June 2020

*Correspondence:

Dr. Nikhil Sebastian,

E-mail: nikhilsebastian571@gmail.com

Copyright: (C) the author(s), publisher and licensee Medip Academy. This is an open-access article distributed under the terms of the Creative Commons Attribution Non-Commercial License, which permits unrestricted non-commercial use, distribution, and reproduction in any medium, provided the original work is properly cited.

\begin{abstract}
Background: Caesarean delivery is one of the commonly performed surgical procedures in obstetrics in today's practice. The objective of this study was to estimate the overall incidence and indications of primary caesarean delivery among multiparous women and to study the immediate maternal and perinatal outcome.

Methods: It was a prospective observational study done in Sikkim Manipal Institute of Medical Science, Sikkim, India. It included all pregnant women after 28 weeks of gestation who had normal vaginal delivery in previous pregnancy but underwent caesarean delivery during current pregnancy $(n=120)$ from January 2016 to December 2016. Authors collected data using a pro forma. Relevant history including demographic details, relevant clinical, laboratory and radiological examination, indication for caesarean delivery, details of delivery and neonate, and duration of hospital stay were noted. Data was described using descriptive data like mean and percentages.

Results: Out of 1646 deliveries conducted, $49 \%$ were by caesarean section. It included $7.29 \%$ primary caesarean delivery in multigravida. Majority of women (27\%) were in the age group 25-29. Maternal request was the commonest indication for caesarean delivery (21.66\%). Atonic PPH was the commonest intraoperative complication $(2.5 \%)$. Surgical site infection was the commonest post-operative morbidity $(3.33 \%)$. There were 51 perinatal morbidity and 2 perinatal mortality. There was no maternal mortality.

Conclusions: Caesarean section rates in this study was higher than WHO recommendation (15\% versus $49.69 \%$ ). This shift in trend can be attributed to higher number of maternal request for caesarean delivery which can be avoided by good analgesic facility and good counselling.
\end{abstract}

Keywords: Maternal and perinatal outcome, Multigravida, Primary caesarean delivery

\section{INTRODUCTION}

Caesarean delivery is one of the commonly performed surgical procedure in Obstetrics in todays practice. Caesarean births have become safer than it used to be in the past by the introduction of better anaesthesia, antibiotics, blood transfusion facility and newer surgical techniques. It is however not safer than uncomplicated normal vaginal deliveries. There is a rising trend in the caesarean delivery rates worldwide with the indications changing over the years. Worries over such increase have led the World Health Organization to advice that caesarean delivery rate should not be more than $15 \%$, with some evidence that caesarean delivery rates above $15 \%$ are not associated with additional reduction in maternal and neonatal mortality and morbidity., Caesarean delivery is not the answer for all obstetric problems but is an excellent solution when applied judiciously. For the past few years there has been a concern about the increase in caesarean delivery rates. The caesarean delivery rates at population level in India seem to be $17.2 \%$ according to National Family Health Survey 2015-2016 (NFHS-4). The caesarean delivery rate reported in Australia ranges from $28 \%$ in Tasmania to $33.1 \%$ in Queensland. "Mortality is normally the only outcome considered in the analyses. Maternal and new 
born morbidity (e.g.: obstetric fistula, birth asphyxia) or psychological and social wellbeing (e.g.: maternal-infant relationship, women's psychological health or ability to successfully initiate breast feeding) as well as long term paediatric outcome should be considered when estimating a rate that would achieve optimal outcomes". 4 Various indications have been observed for caesarean delivery and caesarean delivery on maternal request has been found be one of the reasons for increase in caesarean delivery rates. Hence, authors conducted a study to estimate the overall incidence and various indications of primary caesarean delivery among multiparous women and to analyse their demographic and clinical profile at Sikkim, India. Authors also aimed to study the immediate maternal and perinatal outcome among these women.

\section{METHODS}

This study consisted of analysis of cases where caesarean delivery was done for the first time in parous women, who had previous vaginal deliveries. In the present study, multigravida means second gravida and above, each of whom has had a previous vaginal delivery of a viable neonate.

It was a prospective observational study of 120 cases of caesarean delivery done for the first time in multigravida admitted at Central Referral Hospital, Gangtok attached to Sikkim Manipal Institute of Medical Sciences, Sikkim, India. The study period was $1^{\text {st }}$ January, 2016 to $31^{\text {st }}$ December, 2016.

\section{Inclusion criteria}

- All multiparous women who underwent caesarean delivery after 28 weeks for the first time who had delivered vaginally in previous pregnancies.

\section{Exclusion criteria}

- Pregnancy of less than 28 weeks.

- Previous caesarean delivery or any uterine surgery

Details were recorded once the woman was admitted to the hospital and till, she was discharged. History of the patients was taken at admission with reference to present pregnancy and also previous obstetric history.

General nutritional status, height and stature were noted. Presence of anaemia and edema was recorded. Systemic examination of heart and lungs was done. Vital data like pulse rate, blood pressure, respiratory rate and temperature were recorded.

By obstetrical examination period of gestation, presentation, position was assessed.

Vaginal examination was done to determine Bishop's Score, presence or absence of membranes and to assess adequacy of the pelvis.
For all woman in the study, urine and blood investigations including $\mathrm{Hb}$, blood grouping and typing, total and differential count were performed. Special investigations like liver function test, renal function test done when required. Ultrasonography was done in most of the cases to rule out congenital anomalies, and for estimation of gestational age and for placental localization. Intrapartum cardiotocography was done in cases when indicated.

Labour was monitored for progress and also a check was kept to detect fetal or maternal distress. Decision for caesarean delivery was based on clinical evaluation of progress of labour, fetal condition, and also maternal condition. Types of anesthesia were decided by the anesthetist. Patients who were anemic received compatible blood transfusion if required. All intraoperative details were noted and complications managed promptly. All cases were attended by pediatrician.

Postoperative period was monitored and all complications were managed promptly.

The new-borns were examined daily for any complications noted and managed accordingly.

Patients with uneventful postoperative period were discharged on post-operative day 4.

Woman without sterilization were advised spacing methods and mandatory hospital delivery in next pregnancy.

\section{Statistical analysis}

Data was entered in Microsoft excel and then transferred to SPSS version 16 for analysis. Data was described using descriptive data like mean and percentages.

\section{RESULTS}

There were 1646 deliveries during the period of one year which included $818(49.69 \%)$ deliveries by caesarean delivery. Among the total caesarean delivery 120 (7.29\%) were primary caesarean delivery in multigravida. $27 \%$ of the women were of the age group 25-29. There were 39 (33\%) women who were referred from Government hospitals of Sikkim. Maternal request was the most common indication for caesarean delivery (Table 1) which was done in $26(21.66 \%)$ women. Atonic PPH was the commonest intraoperative complication seen in 3 $(2.5 \%)$ women. Maternal morbidity was seen in 21 $(17.5 \%)$ cases (Table 2). Surgical site infection was the commonest post-operative morbidity seen in 4 (3.33\%) women. There were $7(5.83 \%)$ women who required blood transfusion at some stage of hospital stay. Perinatal morbidity was seen in $51(42.5 \%)$ cases (Table 3) and perinatal mortality was seen in 2 cases. There was no 
maternal mortality in the present study. The average hospital stay was 7 days.

Table 1: Indications of primary caesarean delivery in multiparous women.

\begin{tabular}{|c|c|c|}
\hline Indications & $\begin{array}{l}\text { Number of } \\
\text { patients }\end{array}$ & Percentage \\
\hline Malpresentations & 17 & $14.16 \%$ \\
\hline Breech & 11 & $9.16 \%$ \\
\hline Transverse lie & 5 & $4.16 \%$ \\
\hline Compound presentation & 1 & $0.83 \%$ \\
\hline Antepartum hemorrhage & 7 & $5.83 \%$ \\
\hline Placenta previa & 5 & $4.16 \%$ \\
\hline Abruptio placenta & 2 & $1.66 \%$ \\
\hline $\begin{array}{l}\text { Cephalopelvic } \\
\text { disproportion }\end{array}$ & 6 & $5 \%$ \\
\hline Fetal distress & 23 & $19.16 \%$ \\
\hline IUGR & 3 & $2.5 \%$ \\
\hline Cord prolapse & 2 & $1.66 \%$ \\
\hline Deep transverse arrest & 1 & $0.83 \%$ \\
\hline Failed induction & 12 & $10.00 \%$ \\
\hline Non-progress of labour & 15 & $12.5 \%$ \\
\hline Preeclamptic-toxaemia & 1 & $0.83 \%$ \\
\hline Multiple pregnancy & 4 & $3.33 \%$ \\
\hline Maternal request & 29 & $24.16 \%$ \\
\hline
\end{tabular}

Table 2: Operative complications.

\begin{tabular}{|c|c|c|}
\hline $\begin{array}{l}\text { Intra-operative } \\
\text { complications }\end{array}$ & Frequencies & Percentage \\
\hline Postpartum hemorrhage & 3 & $2.5 \%$ \\
\hline Uterine extension & 2 & $1.66 \%$ \\
\hline Total & 5 & $4.16 \%$ \\
\hline \multicolumn{3}{|c|}{ Post-operative complications } \\
\hline Surgical site infection & 4 & $3.33 \%$ \\
\hline Paralytic ileus & 2 & $1.66 \%$ \\
\hline $\begin{array}{l}\text { Respiratory tract } \\
\text { infection }\end{array}$ & 1 & $0.83 \%$ \\
\hline Post-partum hemorrhage & 4 & $3.33 \%$ \\
\hline Urinary tract infection & 2 & $1.66 \%$ \\
\hline Puerperal fever & 3 & $2.5 \%$ \\
\hline Total & 16 & $13.33 \%$ \\
\hline \multicolumn{3}{|l|}{ Type of complications } \\
\hline Intra-operative & 5 & $4.16 \%$ \\
\hline Post-operative & 16 & $13.33 \%$ \\
\hline Total & 21 & $17.5 \%$ \\
\hline
\end{tabular}

\section{DISCUSSION}

In this study the incidence of primary caesarean delivery in multipara was $7.29 \%$ which is comparable with Himabindu $\mathrm{P}$ et al study (7\%). ${ }^{5}$ These cases were studied with respect to the indications for caesarean deliveries, postoperative morbidity, maternal morbidity and mortality, and perinatal morbidity and mortality. The studies on which WHO based the $15 \%$ recommendation
30 years ago were limited by either having incomplete data or relying on averaged caesarean delivery rates from multiple years without accounting for year to year variation in these estimates. ${ }^{6}$ Maternal and fetal morbidity was not taken into account in these rates.

Table 3: Neonatal complications.

\begin{tabular}{|lll|}
\hline NICU admission & $\begin{array}{l}\text { Number } \\
\text { of babies }\end{array}$ & \begin{tabular}{l} 
Percentage \\
\hline Neonatal jaundice
\end{tabular} \\
\hline Birth asphyxia & 12 & $17.74 \%$ \\
\hline Prematurity & 7 & $9.67 \%$ \\
\hline $\begin{array}{l}\text { Meconium aspiration } \\
\text { syndrome }\end{array}$ & 2 & $5.64 \%$ \\
\hline Small for gestational age & 1 & $1.61 \%$ \\
\hline Fracture & 1 & $0.80 \%$ \\
\hline TTN & 5 & $0.80 \%$ \\
\hline Low birth weight & 1 & $4.03 \%$ \\
\hline Total & 51 & $0.80 \%$ \\
\hline
\end{tabular}

WHO issued a new statement in 2015 headlining the importance of providing caesarean deliveries to women in need, rather than striving to achieve a specific rate. ${ }^{7}$ In the present study $33 \%$ of the cases were referred from public health centres and district hospitals. Since the study hospital is the only tertiary referral centre in Sikkim, exclusively high-risk cases were referred for delivery. Most common medical problem encountered in the present study was anaemia (20\%) in 24 cases, among which 7 patients required blood transfusion. Since anaemia is a major health problem especially in India, a woman is unable to cope up with extra blood loss of caesarean delivery and require blood transfusions. Therefore women, especially multigravida need good supplements and authors need to improve their nutritional status. In the present study maximum numbers of women undergoing primary cesarean delivery in multigravida were in the age group of 25-29 years (27\%). There were $23 \%$ patients above the age of 40 years. This may be due to older child bearing women and delay in childbirth in Sikkim. Incidence of malpresentations in the present study is $14.16 \%$. Malpresentations are more common in a grand multi and are favored by a pendulous abdomen and lordosis of the lumbar spine. Incidence of fetal distress in the present study is $19.19 \%$. This can be attributed to frequent use of cardiotocogram in these recent years as compared to previous decades.

One of the most significant findings of this study was that caesarean delivery on maternal request without any coexisting condition appeared to be the most common indication for elective cesarean delivery in multigravida which constituted around $24.16 \%$ elective caesarean performed in 2016 (Table 1). Many women opt for elective caesarean delivery due to the fear of episiotomies, long painful labours, difficult instrumental deliveries, pelvic floor trauma and subsequent incontinence that are associated with vaginal births. ${ }^{8}$ One 
study has reported an association between fear of childbirth in late pregnancy and subsequent emergency caesarean delivery 105 . Negative expectations and fear of childbirth have been related to a history of depression, anxiety, lack of support, a previous negative birth experience and a previous urgent or emergency caesarean delivery. ${ }^{9,10}$ Absence of maternal mortality in our study group may be attributed to efficient emergency obstetric services and blood bank facilities. It may also be true that intensive care available for critical obstetrical patients at hospital have contributed in the decrease in maternal mortality.

Among the post-operative complications (Table 2), postpartum hemorrhage was the most common (3.33\%) along with surgical site infection (3.33\%). Puerperal fever was seen in $2.5 \%$ cases which was treated with higher antibiotics. Post-partum hemorrhage was treated by blood transfusion and transfusion of blood components as and when necessary. Wound infection requiring secondary suturing was done in 4 cases. Paralytic ileus was managed conservatively with ryles tube aspiration and IV fluids. The incidence of perinatal mortality is very low compared to that of other studies. There was one still birth and one early neonatal death in the study. This may be due to the use of cardiotocogram in the recent decades to detect fetal distress and availability of OT in cases of emergency. Early recognition of complications, timely intervention and better NICU care has decreased fetal loss and also improved pregnancy outcome.

The study was done in Central Referral Hospital of Sikkim which handles majority of deliveries in the state. Hence the study population reflects well on the trend of caesarean delivery in Sikkim, India. It was a prospective study which included all multiparous women undergoing primary caesarean delivery hence there was no case selection bias. This study focused on maternal and neonatal morbidity related to caesarean delivery among multigravida while many previous studies focused only on mortality rates.

One of the limitations of the study was small sample size. The study also failed to compare the morbidity and mortality in normal vaginal deliveries which would have given us a better idea about the complications associated with child birth.

The study should make an effort to compare both groups separately. Another limitation was the arbitrary assignment of indication for caesarean delivery. Some had multiple indications and authors assigned the most appropriate indication. This could be avoided by classifying caesarean delivery according to Robson's 10 group classification.

The higher incidence of caesarean delivery may be due to the fact that $24.16 \%$ of the patients underwent caesarean delivery on maternal request. This can be avoided by good analgesic facility and good antenatal counselling.
There was no maternal mortality in this study which was due to good quality emergency obstetric services and blood bank facility. "Mortality is normally the only outcome considered in the analyses. Maternal and new born morbidity (e.g. obstetric fistula, birth asphyxia) or psychological and social wellbeing (e.g. maternal-infant relationship, women's psychological health or ability to successfully initiate breast feeding) as well as long term pediatric outcome should be considered when estimating a rate that would achieve optimal outcomes."4

It has been observed that a woman who has had a vaginal delivery is more likely to undergo vaginal delivery in her subsequent childbirths. However, she may still require a caesarean delivery for various indications to avoid maternal and fetal mortality and morbidity. This study reemphasizes on the need of proper antenatal care and careful vigilance in the management of labour. Previous vaginal delivery should be regarded only as an optimistic historical fact and not a diagnostic criterion for spontaneous vaginal delivery. This study aim should be to bring down the maternal and fetal mortality as well as morbidity rather than only to decrease the caesarean delivery rates.

\section{Funding: No funding sources Conflict of interest: None declared}

Ethical approval: The study was approved by the Institutional Ethics Committee Sikkim Manipal Institute of Medical Science (IEC No: IEC/345/15-068) on 14 ${ }^{\text {th }}$ October 2015.

\section{REFERENCES}

1. World Health Organization. Monitoring emergency obstetric care: a handbook. Geneva, Switzerland; 2009.

2. Althabe F, Belizan JM. Cesarean delivery: the paradox (comment). Lancet. 2006;368(9546):1472-3.

3. Stavrou EP, Ford JB, Shand AW, Morris JM, Roberts CL. Epidemiology and trends for cesarean delivery births in New South Wales, Australia; a population-based study. BMC Preg Childbirth. 2011;11:8.

4. Betrán AP, Zhang J, Torloni MR, Gülmezoglu AM. Determination of a single, universal threshold for caesarean section rate is not the way forward. BMJ Evid Based Med. 2016;21(6):237.

5. Himabindu P, Sundari MT, Sireesha KV, Sairam MV. Primary cesarean delivery in multipara. IOSRJDMS. 2015;14(5):22-5.

6. Molina G, Weiser TG, Lipsitz SR, Esquivel MM, Uribe-Leitz T, Azad T, et al. Relationship between cesarean delivery rate and maternal and neonatal mortality. JAMA. 2015;314(21):2263-70.

7. World Health Organization. WHO statement on caesarean section rates. World Health Organization; 2015 . Available at: https://apps.who.int/iris/bitstream/handle/10665/161 
442/WHO_RHR_15.02_ita.pdf. Accessed on $12^{\text {th }}$ April 2020.

8. Mould TA, Chong S, Spencer JA, Gallivan S. Women's involvement with the decision preceding their caesarean delivery and their degree of satisfaction. Br J Obstet Gynaecol. 1996;103:1074-7.

9. Wolman WL, Chalmers B, Hofmeyr GJ, Nikodem VC. Postpartum depression and companionship in the clinical birth environment: a randomised controlled study. Am J Obstet Gynaecol. 1993;168:1388-93.
10. Sjögren B, Thomassen P. Obstetric outcome of 100 women with severe anxiety over childbirth. Acta Obstet Gynecol Scand. 1997;76:948-52.

Cite this article as: Sebastian N, Pradhan A, Lucksom PG. Changing trends in the indication of caesarean delivery in multigravida- experience from a referral center in Eastern India: a prospective study. Int J Reprod Contracept Obstet Gynecol 2020;9:3367-71. 